\title{
Techno-Economic Analysis of a Commercial Factory's Renewable Energy System Replacement Alternatives
}

\author{
Jake Stott \\ School of Computing, Engineering \& \\ Digital Technologies \\ Teesside University \\ Middlesbrough, United Kingdom \\ jake.stott@live.co.uk
}

\author{
Gobind Pillai \\ School of Computing, Engineering \& \\ Digital Technologies \\ Teesside University \\ Middlesbrough, United Kingdom \\ g.g.pillai@tees.ac.uk
}

\author{
Neville Winter \\ School of Computing, Engineering \& \\ Digital Technologies \\ Teesside University \\ Middlesbrough, United Kingdom \\ n.winter@tees.ac.uk
}

\begin{abstract}
Renewables typically have a finite life expectancy of around 20 to 30 years. An existing wind energy system for a large commercial factory in the rural area of Barnard Castle, United Kingdom (UK) is nearing the end of its usable life. The existing system is operating at $8 \%$ load factor, providing only 5 $\%$ of the site annual load. A techno-economic assessment of three renewable energy proposals will ensure the site's energy strategy is successful. Three proposals were examined, to continue with the current system until failure, to overhaul the current system and prolong its usable life, or to replace the wind turbines with a rooftop photovoltaic (PV) system. The Net Present Value, Payback Period, Levelised Cost of Electricity and the equivalent Carbon Dioxide emissions were compared for each alternative. The photovoltaic system was the unanimous choice. The Analytical Hierarchy Process was used to systematically select the most appropriate PV module technology for the proposed system, based on the most important factors. Seven different PV module variants were selected and given weighted ratings to determine the most suitable model, the outcome of this was the SunPower SPRMAX2 360 model. This decision was verified by the Consistency Ratio which indicated an informed decision had been made.
\end{abstract}

Keywords-Photovoltaic, Wind, Analytical Hierarchy Process (AHP), Net Present Value (NPV), Payback Period (PBP), Levelised Cost of Electricity (LCOE)

\section{INTRODUCTION}

Renewable energy is key to large commercial operations to ensure that they can meet net-zero greenhouse gas (GHG) emissions by 2050 in line with legislative requirements. Renewable energy systems have a limited usable life expectancy, typically this is in the region of 20 to 30 years depending on the technology used. Wind generation generally has a longer life expectancy than that of photovoltaics (PV). There is a volume of research on choosing renewable technologies for first time installations based on life cycle analysis [1]. However, there is limited knowledge around decommissioning of renewable assets and the necessary governing policies. An initial generalised investigation has been completed in [2] which touches on renewable energy decommissioning.

This paper aims to provide a suitable approach that analyses the potential replacement strategies for ageing wind generation assets at commercial installations as in the case of the large commercial factory in the rural area of Barnard Castle, United Kingdom (UK) investigated in this work.

Techno-economic assessments of three alternative renewable energy system proposals are conducted to determine which direction to steer the site's renewable energy strategy. The first proposal is to continue with the two existing wind turbines until failure, the second is to overhaul the current system and prolong its usable life and the third is to replace the wind turbines with a rooftop PV system.

Unlike wind turbine systems which could replace the current system, there is plenty of choice in terms of PV. PV modules come in numerous different shapes, sizes and materials, each with different properties that impact the overall output power. Among the multi-criteria decisionmaking methods available [1]. Analytical Hierarchy Process (AHP) has been selected and will be used to compare seven different commercially available PV module alternatives and determine which module is the best suited for this installation as it is a proven decision-making process.

The current system will be compared to the proposed alternatives in terms of generation capability and effectiveness along with economic indicators such as Net Present Value, Payback Period, Levelised Cost of Electricity and the equivalent Carbon Dioxide emissions.

\section{TECHNICAL ASSESSMENT}

The comparison of the renewable generation options will be broken down into three proposals:

1) Proceed with the current $225 \mathrm{~kW}$ wind turbines until the end of their usable life in 8-years' time.

2) Overhaul the current $225 \mathrm{~kW}$ wind turbines over 12months to prolong usable life to 15 -years.

3) Replace the current wind turbines with a $1 \mathrm{MW}$ photovoltaic system with a 25 -year usable life.

\section{A. Current Wind Turbine Generation}

Currently there are two Vestas V27 $225 \mathrm{~kW}$ Wind Turbine Generators (WTG) providing renewable energy to the Barnard Castle site. The turbines were initially commissioned in 1993 at a site in the Netherlands before being purchased second-hand and installed in 2004.

Recent export data to the site Building Management System (BMS) shows that in 2020, 313MWh of electricity was generated by the two turbines, which is approximately $8 \%$ of the rated turbine annual output, this can be seen in Fig. 1. This equates to approximately $5 \%$ of the $6.7 \mathrm{GWh}$ of electricity used by the site in 2020 .

It is clear from Fig. 1 that the average wind speed for the location is ideal for WTG, the cut-in speed is $3.5 \mathrm{~m} / \mathrm{s}$ and cutoff speed is $25 \mathrm{~m} / \mathrm{s}$, which suggests that the turbines should have a much higher load factor.

The manufacturer indicates that the serviceable life of the turbines is 20 years, before installation at Barnard Castle, the 
generators were re-wound and the turbine was mechanically overhauled to prolong the serviceable life. To date, the turbines have been annually serviced, however they are approaching 30 years old, so operation is restricted to wind speeds $<15 \mathrm{~m} / \mathrm{s}$ to prolong service life. This is why the load factor is so low in comparison to typical onshore WTG load factors of $26.2 \%$ [3].

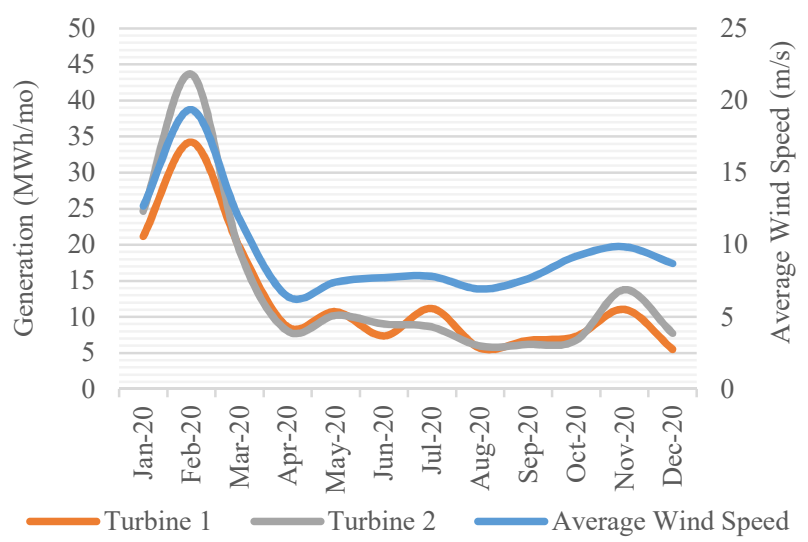

Fig. 1. 2020 Wind Turbine Output and Average Monthly Wind Speed

\section{B. Current Wind Turbine Generation Overhaul}

Based on the most recent Non-Destructive Testing results during periodic maintenance, it was observed that the physical wind turbine rotors, blades and towers are in a good state of repair. Therefore, complete replacement of the towers seems excessive when an overhaul would extend the operable life and improve reliability.

A quotation from the contracted maintenance company responsible for the wind turbines indicates that an entire overhaul of the turbines mechanical systems (pitch, yaw, main drive, gearboxes and brake) and electrical systems (generator rewind and control system upgrade) would be in the region of $£ 200,000$.

It is anticipated that performing this upgrade would result in a $25 \%$ increase in load factor of the turbines from $8 \%$ to $10 \%$ which equates to an increase of $80,000 \mathrm{kWh}$ per annum.

\section{Analytical Hierarchy Process for PV module Selection}

Unutilised commercial roof space is an ideal candidate for a photovoltaic (PV) installation given that the system can be integrated within the existing building's footprint. The first step when designing a PV system introduces a major dilemma to design engineers - which PV module is best for this application?

PV electricity generation in the UK increased by 71.489 $\%$ in the 5-years from 2015 to 2019 [3], this has resulted in the market for PV modules becoming inundated with different manufacturers and panel variants. PV modules come in all different shapes, sizes and materials, each with different properties that impact the overall output power. Typically, among the commercially available modules, monocrystalline panels are the most efficient, followed closely by polycrystalline and amorphous (thin film). Different applications are suited to different materials, particularly based on location, shape and cost.

To better address this dilemma, Analytical Hierarchy Process (AHP) has been used to provide a decision-making process capable of evaluating the fundamental factors, weighting several PV module variants to determine the best solution. This is a mathematical analysis process developed by Thomas Saaty [4] to solve complex decisions that contain multiple criteria.

In the introduction to the AHP methodology [5], it is shown that the first step in AHP is to decompose the complex decision and generate the hierarchy of the goal, the criteria and the alternatives. In this case, the goal is the selection of the best PV module, the criteria consist of the underlying PV module characteristics that would achieve the goal and the alternatives are the PV module options available.

The constructed hierarchy can be seen in Fig. 2 and is the base of the AHP process. The PV module alternatives chosen for this study as well as the best module selection criteria are shown in Fig. 2. The first step of the AHP process is to complete the pairwise comparison matrix of $n$ criteria, where $n$ in this case is 8 , such as (1).

$$
A=\left[\begin{array}{cccc}
a_{11} & a_{12} & \cdots & a_{1 n} \\
a_{21} & a_{22} & \cdots & a_{2 n} \\
\cdots & \cdots & \cdots & \cdots \\
a_{n 1} & a_{n 2} & \cdots & a_{n n}
\end{array}\right]
$$

$a_{i j}$ indicates how much more important the $i^{\text {th }}$ objective is than the $j^{\text {th }}$ objective, where $i$ is the row and $j$ is the column. It is also necessary that $a_{i i}=1$ and $a_{i j}=1 / a_{i j}$. Each value in the comparison matrix is based on a predetermined scale of importance rated 1-9, shown in Table 1.

TABLE 1 AHP SCALE OF IMPORTANCE

\begin{tabular}{|c|c|}
\hline Numerical Value of $\boldsymbol{a}_{\boldsymbol{i} \boldsymbol{j}}$ & Definition \\
\hline 1 & $i$ and $j$ are equally important \\
\hline 3 & $i$ is slightly more important than $j$ \\
\hline 5 & $i$ is more important than $j$ \\
\hline 7 & $i$ is much more important than $j$ \\
\hline 9 & $i$ is extremely important compared to $j$ \\
\hline $2,4,6,8$ & Intermediate values \\
\hline
\end{tabular}

Once the pairwise comparisons have been completed, the geometric mean for $i$ rows must be calculated using (2) before the normalised weight $\left(\mathrm{A}_{\mathrm{w}}\right)$ of each criterion can be determined using (3).

$$
\begin{gathered}
G M_{i}=\sqrt[n]{a_{i 1} a_{i 2} a_{i 3} \cdots a_{i n}} \\
{\left[\begin{array}{c}
A_{w 1} \\
A_{w 2} \\
\cdot \\
\cdot \\
A_{w n}
\end{array}\right]=\left[\begin{array}{c}
G M_{i 1} \\
G M i_{2} \\
\cdot \\
\cdot \\
G M_{i n}
\end{array}\right] \times \sum_{i 1}^{i n} G M_{i}}
\end{gathered}
$$

Once the normalised weight of each criterion is known, the next step is to verify the consistency of this weighting by calculating the consistency eigenvector $C_{i}$ using (4). Once each consistency eigenvector is calculated, (5) can be used to calculate the eigenvalue of the matrix $\lambda_{\max }$.

The eigenvalue of the matrix $\lambda_{\max }$ is then used to calculate the consistency index $(C I)$ which in turn is used to determine the consistency ratio $(C R)$. 


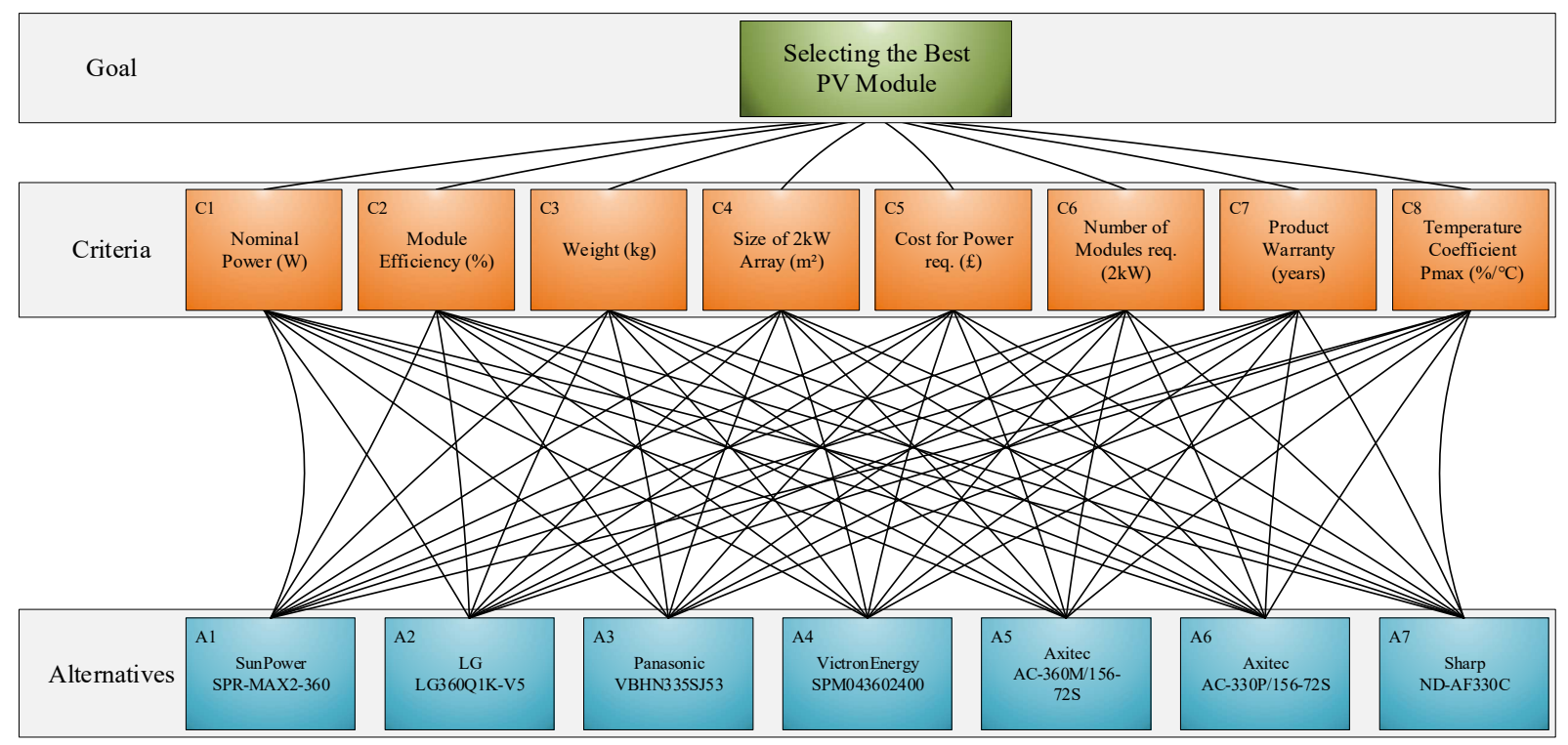

Fig. 2. Construction of Hierarchy for Best PV module Selection using AHP

TABle 2 Pairwise Comparisons of PV MOdule Selection CRiteria

\begin{tabular}{|c|c|c|c|c|c|c|c|c|c|c|c|}
\hline & $\mathbf{C}_{\mathbf{1}}$ & $\mathbf{C}_{\mathbf{2}}$ & $\mathbf{C}_{\mathbf{3}}$ & $\mathbf{C}_{\mathbf{4}}$ & $\mathbf{C}_{\mathbf{5}}$ & $\mathbf{C}_{\mathbf{6}}$ & $\mathbf{C}_{\mathbf{7}}$ & $\mathbf{C}_{\mathbf{8}}$ & $\mathbf{G M}$ & $\mathbf{A}_{\mathbf{w}}$ & $\boldsymbol{\lambda}$ \\
\hline $\mathbf{C}_{\mathbf{1}}$ & 1 & 0.25 & 1 & 0.333 & 0.125 & 0.5 & 0.333 & 1 & 0.414 & 0.040 & 8.335 \\
\hline $\mathbf{C}_{\mathbf{2}}$ & 4 & 1 & 4 & 3 & 1 & 3 & 3 & 4 & 2.611 & 0.255 & 8.350 \\
\hline $\mathbf{C}_{\mathbf{3}}$ & 1 & 0.25 & 1 & 1 & 0.2 & 1 & 0.333 & 1 & 0.599 & 0.058 & 8.269 \\
\hline $\mathbf{C}_{\mathbf{4}}$ & 3 & 0.333 & 1 & 1 & 0.333 & 1 & 2 & 3 & 1.037 & 0.101 & 9.067 \\
\hline $\mathbf{C}_{\mathbf{5}}$ & 8 & 1 & 5 & 3 & 1 & 5 & 2 & 8 & 2.967 & 0.289 & 8.016 \\
\hline $\mathbf{C}_{\mathbf{6}}$ & 2 & 0.333 & 1 & 1 & 0.2 & 1 & 0.2 & 2 & 0.583 & 0.057 & 8.745 \\
\hline $\mathbf{C}_{\mathbf{7}}$ & 3 & 0.333 & 3 & 0.5 & 0.5 & 5 & 1 & 3 & 1.443 & 0.141 & 9.187 \\
\hline $\mathbf{C}_{\mathbf{8}}$ & 2 & 0.2 & 1 & 0.5 & 0.2 & 2 & 0.2 & 2 & 0.596 & 0.058 & 8.573 \\
\hline Total & 24.00 & 3.70 & 17.00 & 10.33 & 3.56 & 18.50 & 9.07 & 20 & 10.250 & 1.000 & 68.542 \\
\hline
\end{tabular}

TABle 3 Alternative-Criteria PAirwise COMPARISON Results

\begin{tabular}{|c|c|c|c|c|c|c|c|c|c|}
\hline & & 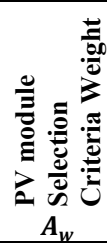 & 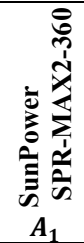 & 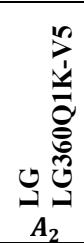 & 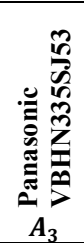 & 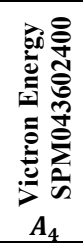 & 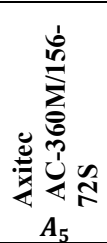 & 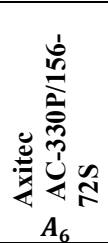 & 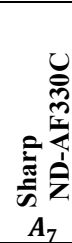 \\
\hline Nominal Power $(W)$ & $C_{1}$ & 0.040 & 0.182 & 0.182 & 0.144 & 0.157 & 0.142 & 0.096 & 0.096 \\
\hline Module Efficiency (\%) & $C_{2}$ & 0.255 & 0.196 & 0.231 & 0.171 & 0.135 & 0.111 & 0.078 & 0.078 \\
\hline Weight (kg) & $C_{3}$ & 0.058 & 0.202 & 0.297 & 0.186 & 0.072 & 0.068 & 0.114 & 0.062 \\
\hline Size of $2 \mathrm{~kW}$ Array $\left(\mathrm{m}^{2}\right)$ & $C_{4}$ & 0.101 & 0.214 & 0.277 & 0.177 & 0.105 & 0.105 & 0.061 & 0.061 \\
\hline Cost for Power req. (£) & $C_{5}$ & 0.289 & 0.175 & 0.040 & 0.104 & 0.107 & 0.102 & 0.188 & 0.284 \\
\hline Number of Modules req. (2kW) & $C_{6}$ & 0.057 & 0.202 & 0.202 & 0.056 & 0.202 & 0.202 & 0.068 & 0.068 \\
\hline Product Warranty (years) & $C_{7}$ & 0.141 & 0.210 & 0.210 & 0.210 & 0.042 & 0.107 & 0.107 & 0.115 \\
\hline Temperature Coefficient Pmax $\left(\% /{ }^{\circ} \mathrm{C}\right)$ & $C_{8}$ & 0.058 & 0.142 & 0.195 & 0.322 & 0.064 & 0.092 & 0.092 & 0.092 \\
\hline
\end{tabular}

$$
\left[\begin{array}{c}
C_{i 1} \\
C_{i 2} \\
\cdots \\
C_{i n}
\end{array}\right]=\left[\begin{array}{cccc}
a_{11} & a_{12} & \cdots & a_{1 n} \\
a_{21} & a_{22} & \cdots & a_{2 n} \\
\cdots & \cdots & \cdots & \cdots \\
a_{n 1} & a_{n 2} & \cdots & a_{n n}
\end{array}\right] \times\left[\begin{array}{c}
A_{w 1} \\
A_{w 2} \\
\cdots \\
A_{w n}
\end{array}\right]
$$

$$
\begin{gathered}
\lambda_{\text {max }}=\frac{1}{n} \sum_{i}^{i n} \frac{C_{i}}{A_{w}} \\
C R=\frac{C I}{R I}
\end{gathered}
$$


The random consistency index $(R I)$ is a randomly generated reciprocal matrix from the same scale, this scale is available in [4]. $C R$ is the ratio of $C I$ to the same order of $R I$ and can be calculated using (6). If $C R \leq 0.1$ then the degree of consistency is evidence of an informed decision [4].

By utilising Microsoft Excel to apply this process to the goal in Fig. 2, Table 2 shows the resultant PV module selection criteria weighting and $C R$. Note: The $C R$ is $<0.1$ which suggests an informed decision has been made for criteria weighting. A similar process of pairwise comparisons must then be conducted between the alternatives (7 PV module variants), this is repeated several times to conduct pairwise comparisons with respect to each criterion. The resultant weightings can be seen in Table 3.

The final step is to multiply each panel alternative by the criteria weighting to obtain the weighted score, the sum of the resultant scores is then the overall score for the PV module. Fig. 3 shows the final PV module weighted scored determined by the AHP process. The highest score overall is deemed the best choice PV module and as such, the best PV module for this scenario is the SunPower SPR-MAX2-360.

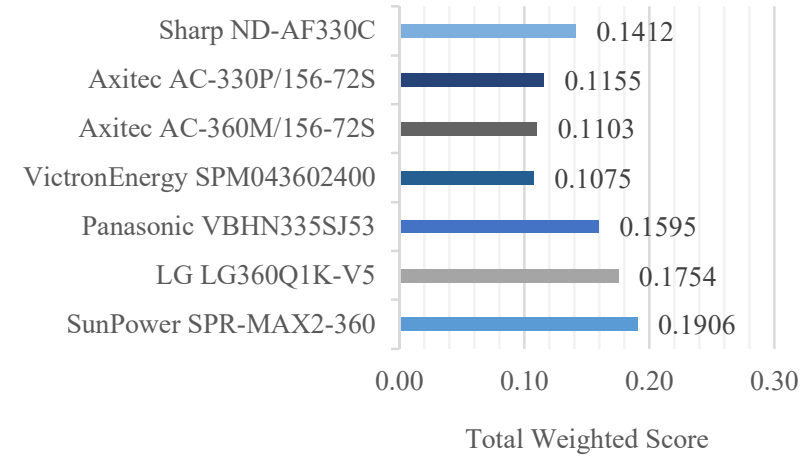

Fig. 3. Overall PV module Weighted AHP Score

\section{Location Solar Data Analysis}

The first and potentially most important factor relating to each location is the amount of usable solar radiation available, solar irradiation data required for this was obtained from the Photovoltaic Geographical Information System [6]. The Photovoltaic Geographical Information System (PVGIS) data are based on the most recent 10-year period available from 2006-2016 and suggests that the optimum angle of panel inclination for the commercial rooftop installation in Barnard Castle would be $40^{\circ}$.

Fig. 4 shows the comparison between the average monthly solar irradiation at this optimally inclined plane and the horizontal plane. Panel installation at this optimum inclination angle results in $17.4 \%$ higher irradiance on the collector plane. Fig. 5 shows the linear forecast of irradiation on the horizontal and optimal planes based on the past 5 years of data, both show a slight downward trend suggesting environmental conditions for PV generation are marginally deteriorating.

Using the SolarEdge Design Suite [7], the proposed system has been modelled and the energy output has been compared with the PVGIS grid-connected model in Fig. 6. The SolarEdge system is a much more detailed representation of the proposed system, comprised of $15 \mathrm{x}$ SolarEdge
SE82.8K Inverters, 2034x SolarEdge P800p Optimisers and 3391x SunPower SPR-MAX2-360 PV modules. Peak production for both models occurs in May, with the SolarEdge system producing $148 \mathrm{MWh}, 34 \mathrm{MWh}$ more than the PVGIS system. Annually, the SolarEdge system produces $927 \mathrm{MWh}$, almost $5 \%$ more than the PVGIS model.

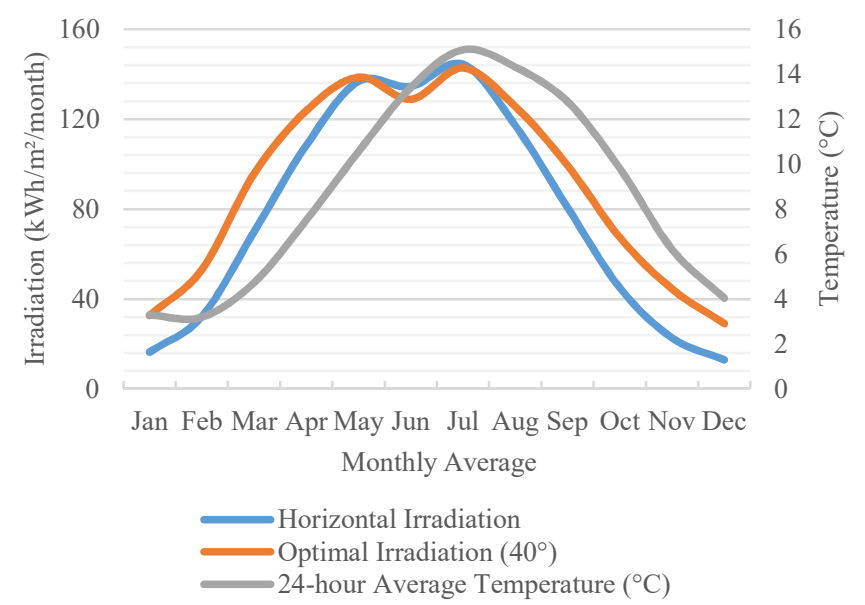

Fig. 4. Monthly Average Irradiation and Temperature
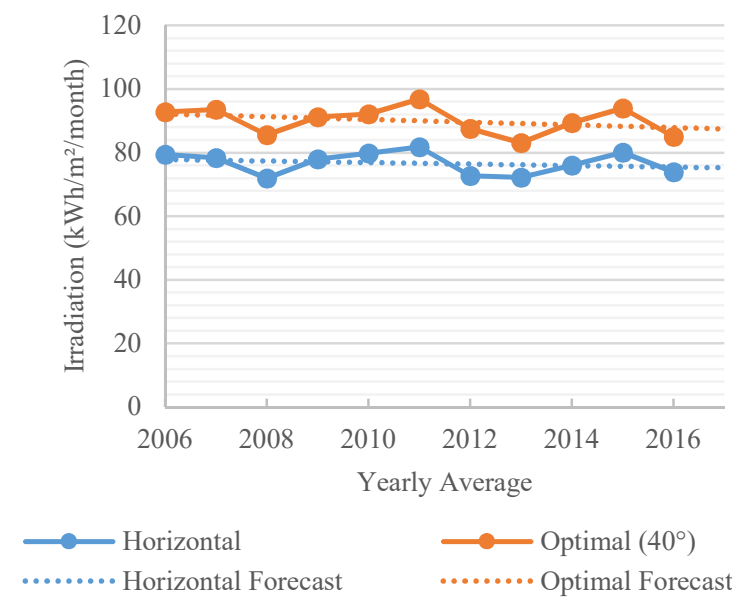

Fig. 5. Yearly Average Irradiation

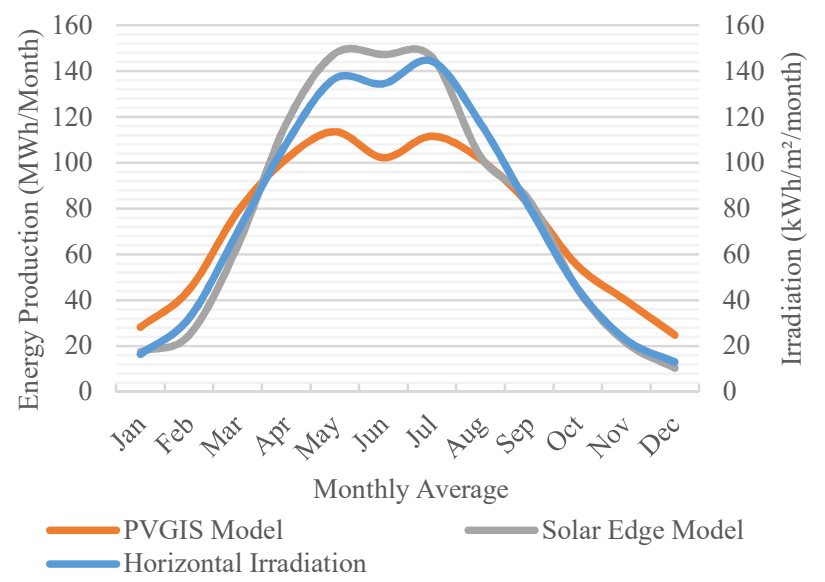

Fig. 6. Average Monthly Energy Production Comparison

Ref [8] also suggested that dust/dirt deposition on the PV module surface is the next most important factor impacting efficiency. As the thickness of dust deposition increases, the PV module output decreases, the outcome of the study can be seen in Fig. 7. 


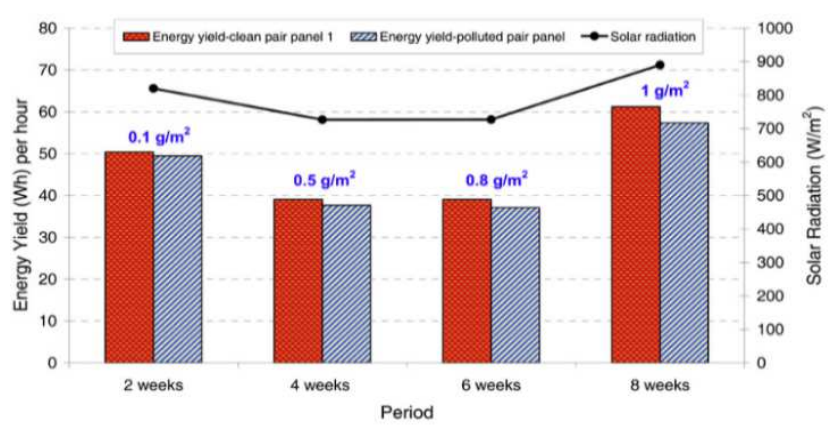

Fig. 7. Energy Yield of the Clean/Polluted PV-Modules according to specific values of Dust Deposition and Mean Solar Radiation [8]

Overall, it was determined that a panel with 8-weeks of dust deposition was $\approx 6.5 \%$ less efficient compared with a clean panel. Two common air quality indices measured are Nitrogen Dioxide $\left(\mathrm{NO}_{2}\right)$ and Particulate Matter $(\mathrm{PM})$, both of which are by-products of road traffic. Elevated levels aren't expected in Barnard Castle, as the town is a rural area and air pollution is relatively low in comparison to a city centre location, for example Greater London [9].

\section{ECONOMIC ANALYSIS}

Each alternative renewable energy proposal will be assessed based on its Net Present Value (NPV), Payback Period, Levelised Cost of Electricity (LCOE) and equivalent Carbon Dioxide emissions based over the next 25-years.

\section{A. Net Present Value}

NPV is extremely important in economic analysis and is the difference between the present value of cash flow and initial capital cost over a project's lifetime, (7) shows the formula to calculate NPV [10].

$$
N P V=\sum_{t=0}^{n} \frac{\text { Revenue }}{(1+r)^{t}}-\text { Initial Cost }
$$

Where:

$n$ is the number of usable years.

$r$ is the discount rate.

For the purpose of this analysis, energy generation is considered revenue while consumption from the grid when renewable energy is unavailable and operation/maintenance costs have been considered as annual costs. The electricity tariff for the site has been determined as $£ 0.138$ per kw, based on the utility charges and consumption in 2020.

Table 4 Net Present Value of Renewable Energy Proposals

\begin{tabular}{|c|c|c|c|}
\hline & NPV Benefit & NPV Cost & NPV Savings \\
\hline Proposal 1 & $£ 137,749.16$ & $£ 410,542.38$ & $-£ 272,793.22$ \\
\hline Proposal 2 & $£ 303,625.38$ & $£ 518,074.64$ & $-£ 214,449.26$ \\
\hline Proposal 3 & $£ 1,485,924.69$ & $£ 1,022,821.00$ & $£ 463,103.69$ \\
\hline
\end{tabular}

A positive NPV indicates that the proposal is economically feasible, whilst a negative NPV indicates an economically unfeasible proposal [11]. Therefore based on Table 4, the $1 \mathrm{MW}$ PV system would be the only feasible proposal given that its NPV of savings over 25-years are positive, this is inclusive of a suggested PV performance degradation factor of $0.5 \%$ per annum [12]. Degradation as a result of dust deposition on the PV module has not been considered, ongoing maintenance of the proposed system will monitor module cleanliness and clean where required to maintain, however if this isn't maintained, the NPV of the PV system would decrease.

\section{B. Payback Period}

The Payback Period (PBP) of a system is a good indicator of how long the system must be operational to make profit after all initial costs and annual costs have been settled. This builds on from the NPV. The NPV indicates whether the system is cost effective over the lifetime considered, however it doesn't say at which point it becomes profitable. Fig. 8 shows a plot of the Payback Period for each proposal.

The first point to note is that for the first 8 years, all three proposals are profitable. Year 12 is the Payback Period for proposal two and three, however, once the wind turbine generators are no longer in operation, the additional electricity cost from the grid means proposals one and two begin losing money in years 8 and 16 respectively. Proposal three for the PV system provides a consistent profit throughout the system lifetime, with a predicted output in year 25 of $905 \mathrm{kWp}$, with an average degredation of $4.8 \mathrm{kWp}$ per year.

\section{Levelised Cost of Electricity}

The LCOE is a measure of the cost of the generated renewable electricity per $\mathrm{kW}$, based on the capital expenditure over the lifetime of the system [13]. The formula for the calculation of LCOE can be seen in $(8,9)$.

$$
\begin{gathered}
L C O E=\frac{\left(N P V_{\text {cost }} \times C R F_{d}\right)}{\text { Annual Energy Production }} \\
C R F_{d}=\frac{r}{\left[1-(1+r)^{-n}\right]}
\end{gathered}
$$

Where:

$C R F_{d}$ is the discount rate Capital Recovery Factor.

Using $(8,9)$, the LCOE for each option has been calculated, it is evident from Table 5 that the $1 \mathrm{MW}$ PV system also has the lowest LCOE, some $35 \%$ (£0.048 per $\mathrm{kW}$ ) cheaper than the 2020 tariff. The difference in LCOE between proposals one and two is negligible, however it can be seen from the NPV that over 25-years, proposal one is $£ 58,000$ cheaper.

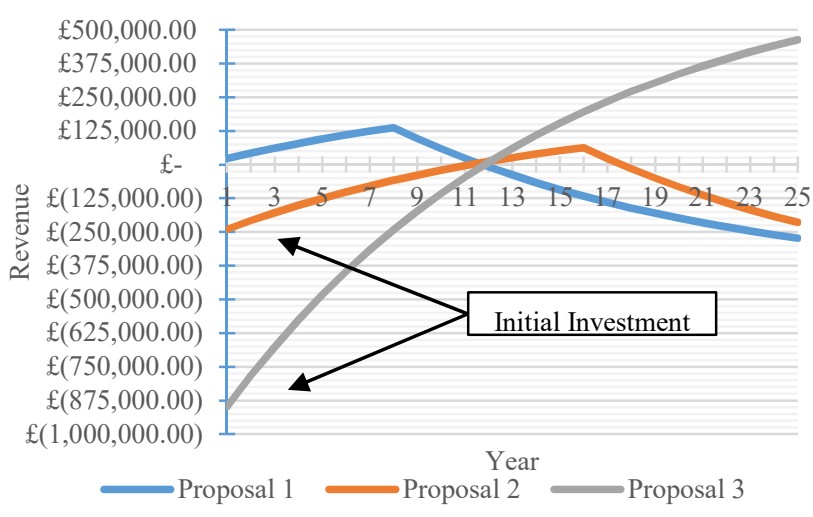

Fig. 8. Payback Period for each Renewable Energy Proposal 
TABLE 5 LEVELISED COST OF ELECTRICITY

\begin{tabular}{|c|c|c|}
\hline & CRFd & LCOE \\
\hline Proposal 1 & 0.0897107 & $£ 0.117 / \mathrm{kW}$ \\
\hline Proposal 2 & 0.0897107 & $£ 0.118 / \mathrm{kW}$ \\
\hline Proposal 3 & 0.0897107 & $£ 0.090 / \mathrm{kW}$ \\
\hline
\end{tabular}

\section{Equivalent Carbon Dioxide Emissions}

Along with the decreasing availability of fossil fuels, reducing carbon emissions/greenhouse gases is paramount in the worldwide fight to combat global warming and is a legal obligation for commercial businesses to be net-zero by 2050 . Utilising renewable energy is one way of doing this. The combined carbon dioxide $\left(\mathrm{CO}_{2}\right)$ equivalent emission factor for electricity generation, transmission and distribution is $0.25091 \mathrm{~kg} \mathrm{CO}$ per kWh electricity [3].

Based on the emission factor and the net generation/ consumption of electricity in the 25 -year period investigated, the equivalent $\mathrm{CO}_{2}$ emissions of each proposal can be calculated, this can be seen in Table 6 .

TABLE 6 CARBON DIOXIDE EMISSIONS

\begin{tabular}{|c|c|c|}
\hline & Net Energy Generation & Equivalent CO Cmissions $_{2}$ Em \\
\hline Proposal 1 & $-2,838,098 \mathrm{kWh}$ & $-712.11 \mathrm{t}$ \\
\hline Proposal 2 & $2,759,262 \mathrm{kWh}$ & $692.33 \mathrm{t}$ \\
\hline Proposal 3 & $25,507,845 \mathrm{kWh}$ & $6400.17 \mathrm{t}$ \\
\hline
\end{tabular}

The immediate point to note is that the PV System results in a net $\mathrm{CO}_{2}$ reduction 10 times greater than the proposal to overhaul the wind turbine generators, reducing emissions by circa 6400 t. The $\mathrm{CO}_{2}$ emissions produced during the system manufacture/install could be in excess of $52 \mathrm{t}$, which are negligible given the $\mathrm{CO}_{2}$ reduction.

\section{CONCLUSION}

The aim of this paper was to assess the current ageing method of renewable energy generation at a commercial factory site at Barnard Castle and ensure that the most appropriate replacement renewable energy solution was selected. The results unanimously identified the roofmounted PV System is the best proposal.

AHP for decision making was used to provide weighted characteristics to select the most suitable module for the proposed PV installation. By using AHP to select the panel, it ensured that an unbiased decision was made. The decision matrix is verified using a Consistency Ratio, a value $<0.1$ suggests that an informed decision has been made, in this situation the Consistency Ratio was considerably lower than this at 0.058 . The outcome of the decision-making process was that the SunPower SPR-MAX2-360 was the best PV module for this installation.

The three identified proposals were techno-economically analysed to determine which would be the best solution. The NPV, PBP, LCOE and Carbon Emissions were used to determine which proposal would be most economically viable. The results showed that in all cases, the proposed $1 \mathrm{MW}$ PV System was the best proposal. The NPV was positive, at $£ 463 \mathrm{k}$ over the 25 -year period, with a PBP of 12 years and LCOE $35 \%$ cheaper than the current electricity tariff at $£ 0.090$ per $\mathrm{kw}$. Considerable $\mathrm{CO}_{2}$ emission reductions were calculated for the PV system, with a net reduction of $6400 \mathrm{t}$, some 10 times better than the next best proposal.

Future work in this area would include a comparison of an equivalently sized wind generation asset to the PV system to determine whether the suggested solution would change and an assessment to determine the feasibility of on-site energy storage.

\section{REFERENCES}

[1] V. Campos-Guzmán, M. García-Cáscales, N. Espinosa and A. Urbina, "Life Cycle Analysis with Multi-Criteria Decision Making: A review of approaches for the sustainability evaluation of renewable energy technologies," Renewable and Sustainable Energy Reviews, vol. 104, pp. 343-366, 2019.

[2] D. C. Invernizzi, G. Locatelli, A. Velenturf and P. E. Love, "Developing policies for the end-of-life of energy infrastructure: Coming to terms with the challenges of decommissioning," Energy Policy, vol. 144, pp. 1-7, 2020.

[3] UK Government, "Digest of UK Energy Statistics (DUKES): renewable sources of energy," July 2020. [Online]. Available: https://www.gov.uk/government/statistics/digest-of-uk-energystatistics-dukes-2020. [Accessed April 2021].

[4] T. L. Saaty, The Analytic Hierarchy Process, New York: McGrawHill, 1980

[5] R. H. Ansah, S. Sorooshian and S. B. Mustafa, "Analytic Hierarchy Process Decision Making Algorithm," Global Journal of Pure and Applied Mathematics., vol. 11, no. 4, pp. 2403-2410, 2015.

[6] European Commission, "Photovoltaic Geographical Information System," 2020. [Online]. Available: https://re.jrc.ec.europa.eu/pvg_tools/en/\#PVP. [Accessed 12 November 2020].

[7] SolarEdge Technologies Inc., "SolarEdge Designer," SolarEdge Technologies Inc., 2021. [Online]. Available: https://designer.solaredge.com/. [Accessed April 2021].

[8] J. K. Kaldellis and A. Kokala, "Quantifying the decrease of the photovoltaic panels'energy yield dueto phenomena of natural air pollution disposal," Energy, vol. 35, no. 12, pp. 4862-4869, 2010.

[9] Air Matters, "Greater London Air Quality," Air Matters, 2021. [Online]. Available: https://air-quality.com/place/unitedkingdom/england/6575f050?lang=en\&standard=daqi_uk. [Accessed 29 April 2021]

[10] G. Pillai and H. A. Y. Naser, "Techno-economic potential of largescale photovoltaics in Bahrain," Sustainable Energy Technologies and Assessments, vol. 27, pp. 40-45, 2018.

[11] S. Abdelhady, "Performance and cost evaluation of solar dish power plant: sensitivity analysis of levelized cost of electricity (LCOE) and net present value (NPV)," Renewable Energy, vol. 168, pp. 332-342, 2020.

[12] D. C. Jordan and S. R. Kurtz, "Photovoltaic Degradation Rates - An Analytical Review," National Renewable Energy Laboratory, Colorado, 2012.

[13] E. Drury, P. Denholm and R. Margolis, "The Impact of Different Economic Performance Metrics on the Perceived Value of Solar Photovoltaics," National Renewable Energy Laboratory, Colorado, 2011. 